\title{
Trajetória do sistema de avaliação do rendimento escolar do Estado do Rio Grande do Sul
}

\author{
Carmen Maria Koetz* \\ Flávia Obino Corrêa Werle**
}

\section{Resumo}

A proposta deste artigo é analisar a institucionalização do Sistema de Avaliação do Estado do Rio Grande do Sul, apresentando-o como uma política de governo, associada ao partido que está no poder. Está organizado por período de governo. Conclui que, a cada mudança de governo, novas concepções e práticas políticas de avaliação educacional foram empregadas no Estado do Rio Grande do Sul, com o intuito de verificar o rendimento dos estudantes.

Palavras-chave: Avaliação externa. Política pública de avaliação educacional. Sistema de avaliação do rendimento escolar do Estado do Rio Grande do Sul - SAERS.

\section{Trajectory of system performance evaluation of the school of Rio Grande do Sul \\ Abstract}

This is a study about the history of the institutionalization of the Evaluation System of the State of Rio Grande do Sul as a public policy for the educational evaluation. The policy changes reflect the election for a new government. The conclusion is that, in any change in government, brings about new concepts and practices related to the educational policies of evaluation were applied in Rio Grande do Sul, in order to check the performance of the students.

Keywords: External Evaluation. Public Policy for Educational Evaluation. System Evaluation of Educational Achievement from the State of Rio Grande do Sul - SAERS.

\footnotetext{
* Mestre em Educação, UNISINOS. Professora da rede pública do Estado do RS. E mail: carmenkoetz@yahoo.com.br

** Pós-doutorado, Universidade do Minho, Portugal. Professora Titular da Universidade do Vale do Rio dos Sinos, UNISINOS. E mail: flaviaw2008@gmail.com
} 


\section{La trayectoria del Sistema de Evaluación del Rendimiento Escolar del Estado de Rio Grande do Sul (Brasil)}

\section{Resumen}

La propuesta de este artículo es analizar la institucionalización del Sistema de Evaluación de la provincia de Rio Grande do Sul, en Brasil, presentándola como una política gubernamental, asociada al partido que está en el poder. Está organizado por período de gobierno. Se concluye que, a cada cambio de gobierno, nuevas concepciones y prácticas políticas de evaluación educacional se emplearon en la provincia con el objeto de verificar el rendimiento de los estudiantes.

Palabras clave: Evaluación Externa. Política Pública de Evaluación Educacional. Sistema de Evaluación del Rendimiento Escolar del Estado de Rio Grande do Sul (SAERS).

\section{Considerações Iniciais}

A política envolve um conjunto de atividades que têm como termo de referência a polis, o Estado, o qual tem como referência a coletividade que o fundamenta. Quando suas ações são justificadas pelo fato de serem exercidas em nome desta coletividade, a ele é atribuída uma "razão de Estado" (BOBBIO, 1986, p. 962). Assim, Estado distingue-se de governo, pois este vincula-se mais aos que estão no poder, a alternância e variabilidade de interesses e orientações, pessoas que representam diferentes orientações ideológicas e se articulam em partidos políticos. Governo pode ser definido "como o conjunto de pessoas que exercem o poder político e que determinam a orientação política de uma determinada sociedade" (LEVI, 1986, p. 553), pessoas que em conjunto detém o poder de governar e, de alguma forma, direcionar as ações realizadas pelas instituições estatais, embora tais instituições, sejam configuradas por elementos normativos que Ihe garantem uma certa estabilidade. Falar em política de Estado significa, portanto, referirmo-nos a um quadro mais estável, mais permanente de ações públicas do que se falarmos em políticas de governo.

Este texto argumenta que, no Rio Grande do Sul, as politicas de avaliação em larga escala implementadas nos últimos anos configuram-se como políticas de governo e não de Estado, por sua presença e supressão relacionada às transformações históricas do quadro político no governo. Embora em nível federal as políticas de avaliação venham sendo realizadas continuamente desde o final dos anos oitenta (BONAMINO, 2002), no Rio Grande do Sul elas, se efetivaram de forma intermitente.

A noção de "geração de políticas educacionais" remete à existência de um "conjunto relativamente articulado de medidas, relacionadas com seu contexto social e político" (FRANCO; BONAMINO; ALVES, 2007, p. 993). Embora os autores reconheçam os problemas de descontinuidade que as politicas educacionais 
brasileiras apresentam, para eles, a partir da década de 1980, esta descontinuidade foi relativamente superada. Em que pese o fato de os autores se estarem referindo a continuidades e descontinuidades das políticas educacionais de âmbito federal, nosso estudo evidencia prevalência de descontinuidades. No âmbito estadual, as políticas não adquiriram, ainda, uma estabilidade, pelo menos no caso de políticas de avaliação em larga escala promovidas sob a responsabilidade da instância estadual no Rio Grande do Sul, ou seja, neste Estado, as políticas de avaliação tem-se afigurado como políticas de governo e não de Estado, com o que elas não têm tido sustentação e continuidade suficientes para configurar uma "geração de políticas".

Por outro lado, as avaliações em larga escala são políticas nas quais afloraram, em diversos momentos, traços performativos e gerencialistas na linha da nova gestão pública cuja proposta enfatiza a profissionalização de base técnica e a gestão orientada em práticas do setor privado (PAULA, 2005). A administração pública gerencial pautase na administração por resultados, na elaboração de planos estratégicos, articulando responsabilidades para com o atendimento aos preceitos legais e com os resultados (BRESSER-PEREIRA, 2008). Argumenta-se neste artigo também que as políticas de avaliação no RS apresentam progressivo cariz performativo e gerencial.

Considera-se que discutir políticas de avaliação em larga escala exige analisálas do ponto de vista do controle, como meio para mudança e na perspectiva de performatividade associada à objetividade dos números e índices. A performatividade ${ }^{1}$ funciona como cultura, assim como tecnologia e "é alcançada mediante a construção e publicação de informações e indicadores" (BALL, 2005, p. 544). As avaliações em larga escala alinham-se à perspectiva de tecnologias voltadas para o desempenho, para a performance. 0 gerencialismo está associado à performatividade, por articular ordem, transparência e classificação.

As avaliações instauram uma necessidade cada vez mais intensa de mais e melhores indicadores que se diversificam e tornam-se complexos ao longo do tempo. 0 gerenciamento se volta para a valorização destes indicadores, seu uso como instrumentos de produção de mudanças, articulando os desempenhos alcançados a premiações e gratificações. Embora as propostas políticas sejam constantemente e em diferentes níveis, modificadas, rearticuladas, passando por processos de bricolage e reinterpretação, a força da performatividade vai-se progressivamente impondo e ganhando espaço nos sistemas de ensino.

\footnotetext{
1 "A performatividade é uma tecnologia, uma cultura e um método de regulamentação que emprega julgamentos, comparações e demonstrações como meios de controle, atrito e mudança. Os desempenhos de sujeitos individuais ou de organizações servem de parâmetros de produtividade ou de resultado, ou servem ainda como demonstrações de “qualidade” ou "momentos” de promoção ou inspeção”, (BALL, 2005, p. 545). “A performatividade é alcançada mediante a construção e publicação de informações e de indicadores, além de outras realizações e materiais institucionais de caráter promocional, como mecanismos para estimular, julgar e comparar profissionais em termos de resultados: a tendência para nomear, diferenciar e classificar” (BALL, 2005, p. 546).
} 
Este estudo 2 trata, pois, da trajetória do Sistema de Avaliação do Estado do Rio Grande do Sul, como política pública de educação, tendo como foco descrever a operacionalização, os objetivos e finalidade deste sistema, a elaboração e composição das provas em cada ano de execução do processo, número de escolas e de alunos participantes. Está organizado por período de governo, dos então governadores Antonio Britto Filho - três primeiras edições (1996/1997/1998), Germano Rigotto uma única avaliação, como projeto piloto vinculado a um Contrato de Gestão (2005) e Yeda Ronrato Crusius (2007/2008/2009).

A implantação do SAEB, em nível nacional na década de 1990, estimulou a implantação de Sistemas de Avaliações em âmbito dos Estados, fazendo com que estes também desenvolvessem seus sistemas de avaliação. Dos vinte e seis Estados e Distrito Federal, dez desenvolvem seu sistema próprio de avaliação. São eles: Alagoas, Ceará, Espírito Santo, Maranhão, Minas Gerais, Paraná, Pernambuco, Rio de Janeiro, Rio Grande do Sul e São Paulo (LOPES, 2007). Os mais antigos são os do Ceará, Mato Grosso do Sul, Paraná, Bahia e São Paulo. Vários, entretanto, foram extintos e, posteriormente, recriados, como os de Mato Grosso do Sul e Bahia. Estes dados se referem a um trabalho publicado em 2007, entretanto, a consulta ao site da Secretaria de Educação do Mato Grosso do Sul e da Bahia apresenta informações diferentes. Mato Grosso do Sul realizou uma avaliação em 2005 e, na Bahia, em 2008, ocorreu a Avaliação Externa do Ensino Médio (AVALIE) que focaliza o desempenho exclusivamente dos alunos das escolas do Ensino Médio, por meio de uma avaliação seriada, que acompanha os alunos ao longo de três anos.

No Rio Grande do Sul, a avaliação ocorreu entre 1996/1998, durante o governo de Antônio Britto Filho (1995/1998) do PMDB, envolvendo todas as escolas da rede estadual de ensino. Posteriormente, no governo de Germano Rigotto (2003 a 2006), do PMDB, foi retomado, em uma única edição, em 2005, envolvendo apenas duas Coordenadorias Regionais de Educação (CREs), já sob a denominação de Sistema de Avaliação do Rendimento Escolar do Estado do Rio Grande do Sul - (SAERS). Mas foi nas edições de 2007 a 2009, governo de Yeda Rorato Crusius (2007 a 2010), do PSDB, que se estabeleceu uma sistemática mais abrangente, tendo a avaliação acontecido, anualmente, aberta a todas as escolas estaduais e redes municipais que manifestassem interesse em participar, bem como às escolas particulares que o desejassem.

\footnotetext{
Este artigo apresenta uma analise de dados da dissertação 0 Sistema de Avaliação do Rendimento Escolar do Estado do Rio Grande do Sul - SAERS: institucionalização, defendida no Programa de PósGraduação em Educação da Universidade do Vale do Rio dos Sinos. Realiza um resgate histórico das políticas educacionais tendo como fontes documentos (leis, decretos, relatórios, projetos), informações veiculadas em jornal do Estado e entrevista semi-estruturada com a chefe da Divisão de Pesquisa e Avaliação Institucional da Secretaria Estadual de Educação do Rio Grande do Sul que participou do planejamento, execução e avaliação do sistema de avaliação no período de 1996 - 98 . A referida dissertação constituiu parte das atividades acadêmicas inseridas no Observatório de Educação, projeto desenvolvido na UNISINOS o qual recebeu apoio da Coordenação de Aperfeiçoamento de Pessoal de Nivel Superior - CAPES - Brasil.
} 


\section{Sistema de Avaliação no período de 1995/1998}

Muitas foram as políticas educacionais desenvolvidas na década de 1990 no Brasil. 0 marco dessas políticas focalizou a descentralização da educação enunciada em três dimensões: administrativa, financeira e pedagógica, resultando em transferência de responsabilidade dos órgãos centrais (União, Estados) para os locais (Municípios, escolas), oportunizando assim, às escolas, maior autonomia.

No Estado do Rio Grande do Sul, estas discussões também estavam presentes. 0 então governador do Estado, Antonio Britto Filho, passou a manter um governo cujo projeto seguia as mesmas diretrizes federais (CAMINI, 2005). Na área educacional as discussões fizeram-se presentes na elaboração e na aprovação, em 14 de novembro de 1995, da Lei 10.576, sobre a Gestão Democrática do Ensino Público. Esta Lei normatizava a eleição de diretores, a composição e função do Conselho Escolar e a autonomia na gestão administrativa, financeira e pedagógica das escolas. No capítulo III, sobre a Autonomia da Gestão Pedagógica, a Lei regulamentava o que se refere à Avaliação Externa, indicando que todos os estabelecimentos de ensino da rede pública seriam anualmente avaliados, através de um Sistema de Avaliação coordenado e executado pela Secretaria Estadual de Educação/RS (SEE/RS), e que os resultados seriam divulgados para cada escola de forma a servir de base para a reavaliação do Plano Integrado do ano seguinte.

A referência desse processo foi o SAEB que, em sua terceira edição, no final do ano de 1995, evidenciou que, para o Estado do Rio Grande do Sul, o "aproveitamento curricular médio apontado, apesar de não ser satisfatório, colocava o Estado em $3^{\circ}$ lugar em relação aos alunos dos demais Estados da Federação" (RIO GRANDE DO SUL, 1996). Como o SAEB não permitia uma visão focalizada de cada unidade escolar emergia a necessidade de criar um sistema próprio de avaliação que diagnosticasse a situação de cada escola. A primeira edição referenciou-se, portanto, em experiências como o SAEB, o Sistema de Avaliação do Rendimento Escolar do Estado de São Paulo (SARESP) e o Sistema Mineiro de Avaliação da Educação Pública (SIMAVE). Tanto o SARESP quanto o SIMAVE vinham acontecendo desde 1992 como uma política pública da avaliação nos seus respectivos Estados. A SEE/RS promoveu a primeira edição de uma avaliação externa, que ocorreu em 1996, seguidas em 1997 e 1998 com a denominação de Sistema de Avaliação das Escolas da Rede Pública Estadual.

Para a primeira edição, em 1996, a SEE/RS elaborou um Projeto de Avaliação contendo o roteiro das principais atividades de implantação - definia o número de escolas, as Delegacias de Ensino (DEs), a seleção de matérias e conteúdos das provas, a constituição da equipe executora, a contratação de serviços de edição, a montagem dos instrumentos e a análise dos resultados. Era um projeto detalhado que apresentava instruções para a aplicação dos testes aos alunos, datas, verificação do material recolhido e relatório de aplicação dos testes, bem como determinava a montagem de uma equipe de processamento, análise, digitação e edição do material. 0 projeto 
objetivava ainda a definição de estratégias para a próxima edição, a necessidade de analisar o desempenho do Sistema Educacional como um todo e gerar informações que subsidiassem o processo de ensino e aprendizagem e a gestão democrática das escolas.

A coordenação estava a cargo do Departamento de Planejamento (DEPLAN) e, a responsabilidade de sua implantação, era da Divisão de Pesquisa e Avaliação Institucional (DPAI). 0 Sistema de Avaliação/1996 apresentava-se dividido em duas fases, a primeira focando a operacionalização dos testes e a segunda relativa a questionários a serem respondidos pelo diretor e membro do Conselho Escolar.

A primeira referente à aplicação de teste aos alunos de $1^{\circ} \mathrm{e} 2^{\circ}$ graus indicava três equipes. A primeira, Coordenação geral, era composta pelos diretores dos departamentos pedagógico, de planejamento e chefia da Divisão de Avaliação. A segunda, descentralizada, formada pela coordenação regional, incluindo Delegados de Educação, a Chefia Pedagógica e o Assessor Técnico, com a função de coordenação, implantação e assessoramento às escolas quanto ao treinamento dos diretores e elaboração do relatório regional. E a terceira formada pela Coordenação local - Escolas -, constituída pelo Diretor, Vice-Diretor e Supervisor Escolar com a incumbência da coordenação, implementação e execução do projeto.

Preliminarmente, as delegacias regionais informavam os dados das escolas estaduais, tendo como referência a Matrícula Real das $2^{a}$, $5^{\text {a }}$ e $7^{\text {a }}$ séries do ensino fundamental e $2^{\text {a }}$ série do ensino médio. Com a finalidade de validação dos conteúdos a serem avaliados constituíram-se equipes de especialistas para assessoramento dos técnicos da Divisão de Pesquisa. Tal como no SAEB, os testes referiam-se à Língua Portuguesa e à Matemática e os alunos responderiam a apenas um, ou seja, quem respondia Português não responderia Matemática e vice-versa.

Após a aplicação dos testes, as respostas eram encaminhadas das escolas para as Delegacias Regionais de Ensino (DE s), e destas para a Fundação de Desenvolvimento de Recursos Humanos (FDRH) ${ }^{3}$, contratada para a elaboração dos relatórios. Foi realizado também um acompanhamento do processo de avaliação com o objetivo de aprimoramento de continuidade do projeto.

Foram construídos dois questionários na segunda fase do Sistema de Avaliação, um para o diretor e outro para o professor representante do Conselho Escolar de cada escola. 0 conteúdo desses instrumentos era semelhante, focando a identificação pessoal e da escola, formação e experiência profissional, estrutura da gestão, avaliação da gestão e considerações sobre a

\footnotetext{
${ }^{3}$ A Fundação para o Desenvolvimento de Recursos Humanos (FDRH) tem o objetivo desenvolver atividades voltadas ao aperfeiçoamento dos servidores estaduais. Ligada à Secretaria da Administração e dos Recursos Humanos. A FDRH trabalha na qualificação e capacitação dos servidores dos órgãos públicos federais, estaduais e municipais, além de realizar concursos públicos e fazer a gestão de contratos de estágios para os órgãos do governo, prefeituras e demais instituições públicas (FDRH, 2011).
} 
primeira fase da Avaliação Externa. Este Sistema de Avaliação foi instituído pelo Decreto/lei n. 36.893, de 2 de setembro de 1996, cuja implantação, implementação e divulgação era de competência da SEE/RS; seu objetivo era, analisar o desempenho do Sistema Estadual de Ensino, subsidiar decisões sobre o processo ensino-aprendizagem e alocar recursos técnicofinanceiros, bem como o replanejamento da proposta pedagógica. Este Decreto estava em consonância com o estabelecido pela Lei 10.576/1995 da Gestão Democrática do Ensino.

A avaliação ocorrida em 24 de outubro de 1996 mobilizou mais de 20.000 professores, além de diretores e técnicos das DEs e da SEE/RS; a segunda fase, de aplicação de questionários aos diretores e professores representantes dos Conselhos Escolares ocorreu em 29/11/1996.

Participaram da avaliação em 1996427 municípios e 3.355 escolas da rede estadual, bem como 454.543 alunos. No total, 3.049 gestores responderam aos questionários de avaliação da gestão escolar (WERLE, 1997, p.273). Havia questões que focalizavam a contribuição do Conselho Escolar na administração escolar, os problemas que dificultaram a gestão escolar, os recursos financeiros repassados via autonomia financeira e a implantação da gestão democrática. São temas que remetem à importância da autonomia administrativa, financeira e pedagógica nas escolas, bem como à participação ativa do Conselho Escolar. Os dados alcançados na avaliação nacional e na estadual, entretanto, não estavam satisfazendo ao esperado pela SEE/RS4 . Para superar a situação foi organizado um Programa de Qualificação de Docentes desenvolvido em 2 níveis: um de Sensibilização e Mobilização e outro de Educação Continuada com ênfase na diversidade e descentralização, focando os professores das disciplinas e séries avaliadas.

Estudos de Bonamino (2002), Freitas (2007) e Pestana (1998) enfatizam as mudanças nas disciplinas, séries, contratação de terceirização de serviços, Matriz de Referência, Teoria de Resposta ao Item e operacionalidade do sistema que vinham ocorrendo no sistema de avaliação nacional. Estas alterações passam também a influenciar o sistema de avaliação do Rio Grande do Sul nas edições de 1997 e 1998, como forma de aperfeiçoamento do sistema de avaliação e superar os baixos índices alcançados. Para Fontanive (2005, p. 161) "Sem dúvida, esta talvez seja a grande contribuição do SAEB: possuir uma métrica nacional e fornecer cooperação técnica para que Estados e Municípios realizem suas avaliações".

Embora o sistema de avaliação RS fosse organizado detalhando a legislação estadual que incorporava demandas históricas referentes à gestão democrática, e sua operacionalização fosse concebida e executada pela SEC/RS, implementada "por dentro" dos órgãos oficiais e estrutura administrativa do Estado, esta afirmativa de Fontanive também se apresenta verdadeira para o RS, pois o formato e conteúdos envolvidos nos testes se constituíam à semelhança do sistema nacional.

4 Em 12 de Março de 1997, a Assessoria de Imprensa do Gabinete do Governador, analisa que através dos resultados da avaliação do SAEB/1995 e do Sistema de Avaliação do Estado/1996 o ensino precisava melhorar para atingir padrões de países desenvolvidos. 
Para a segunda edição do Sistema de Avaliação em 1997, a SEE/RS procedeu a várias inovações. Alterou as séries abrangidas, passando a avaliar os alunos da $4^{\mathrm{a}}$ e $8^{a}$ série do Ensino Fundamental e da $3^{\text {a }}$ série do Ensino Médio nas disciplinas de Língua Portuguesa, onde incluiu uma Redação, e Matemática, bem como a identificar fatores contextuais que interferem no desempenho dos alunos das séries finais de ciclo, mediante um questionário de contexto. Outra mudança significativa foi o envolvimento da comunidade escolar com a participação de representantes do Conselho Escolar, do Circulo de Pais e Mestres junto com o diretor, vice-diretor e supervisor escolar para acompanhar os trabalhos no âmbito da escola. A Federação das Associações dos Municípios do Rio Grande do Sul (FAMURS) ${ }^{5}$, foi chamada para uma parceria abrindo a possibilidade de participação das escolas municipais.

Para a digitação, impressão dos testes e questionários, correção das redações, envelopamento, entrega do material e dos relatórios finais por escola, por DEs ou Associação de Município, foi contratada a Fundação de Apoio da Universidade Federal do Rio Grande do Sul (FAURGS) ${ }^{6}$.

Os conteúdos das disciplinas ${ }^{7}$ de Português e Matemática foram elaborados e validados por professores vinculados a escolas de Ensino Fundamental e Médio especialmente da rede pública e de instituições de ensino superior. Esta edição introduziu, portanto, procedimentos de aproximação com a realidade dos estabelecimentos avaliados e de consideração do conhecimento e valorização profissional dos docentes da rede estadual.

Como na avaliação anterior, cada aluno respondia a apenas uma prova e os alunos que fizessem a prova de Português, responderiam, no dia seguinte da prova, a um questionário de contexto. Nas avaliações externas nacionais, o questionário dirigido a alunos, professores e diretores, objetiva coletar informações sobre o nivel socioeconômico dos alunos e hábitos de estudos dos mesmos. "A análise desses dados busca possiveis correlações entre desempenho escolar, contexto e insumos de ensino" (FREITAS, 2007, p. 108). Da mesma forma, no sistema

5 Federação das Associações de Municípios do Rio grande do Sul (FAMURS). Entidade que representa todos os 496 Municípios gaúchos, por meio das 27 Associações Regionais, que a compõem. Tem como objetivo principal o fortalecimento do municipalismo, a qualificação dos agentes públicos municipais e o assessoramento às prefeituras gaúchas. (FAMURS, 2011). 6 Fundação de Apoio da Universidade Federal do Rio Grande do Sul (FAURGS) é uma entidade criada por iniciativa da Universidade Federal do Rio Grande do Sul (UFRGS). Tem como objetivos: colaborar na elaboração e execução de projetos de pesquisa, ensino e extensão; prestar serviços técnico-científicos remunerados à UFRGS e à comunidade; realizar e promover atividades científicas e culturais; conceder bolsas de estudo e de pesquisa, de graduação, pós-graduação e extensão e promover, difundir e coordenar a cooperação técnica entre organizações e instituições nacionais e estrangeiras (FUNDAÇÃO DE APOIO DA UNIVERSIDADE FEDERAL DO RIO GRANDE DO SUL, 2011).

6 A referencia para os conteúdos foram os programas desenvolvidos nas escolas estaduais de Ensino Fundamental e Médio, a matriz referencial do SAEB, o Programa Experimental de Ingresso do Ensino Superior (PEIES) da Universidade Federal de Santa Maria, livros didáticos e o Projeto de Melhoria da Qualidade de Ensino desta SEC/RS. Os testes enfocavam habilidades que envolviam desde ações de complexidade mínima (conhecimento) até as mais complexas (compreensão e aplicação do que foi apreendido).

7 A Lei 11.126, de 09 de fevereiro de 1998, segue as diretrizes nacionais da Reforma Gerencial. 
de avaliação RS realizado em 1997, a proposta era coletar dados para melhor explicar os resultados e a partir daí, configurar políticas públicas. Dessa segunda edição participaram 7.174 escolas, sendo 3.297 estaduais e 3.877 municipais, de 278 municípios.

A terceira edição do Sistema de Avaliação das Escolas da Rede Pública Estadual e Municipal foi desenvolvida em 1998, apresentando as mesmas caracteristicas da avaliação de 1997. Foi também contratada a FAURGS como prestadora de serviços e as séries avaliadas foram as mesmas da avaliação de 1997. As mudanças mais significativas nesta $3^{\text {a }}$ edição foram a inclusão da disciplina Ciências no Ensino Fundamental e Física, Química e Biologia no Ensino Médio, como também a aplicação de questionários de contexto aos alunos da $8^{\mathrm{a}}$ série do Ensino Fundamental e $3^{\mathrm{a}}$ série do Ensino Médio para levantamento de aspectos da aprendizagem nas disciplinas de Língua Portuguesa e Matemática. Os questionários vinham encartados aos testes de Matemática, Ciências, Física, Química e Biologia, e com o teste de Português, vinha a Redação. Cada aluno respondia a apenas um teste, assim, o aluno que participava da prova de Português fazia a redação e não respondia ao questionário.

Participaram deste processo 316.906 alunos, sendo 271.156 da rede estadual de ensino e 45.750 da rede municipal. Abrangendo todas as escolas estaduais (3.297) e escolas da rede municipal (2.719) totalizando 6.016 escolas.

No ano de 1998 entretanto, anuncia-se um processo diferenciado de gestão da educação no Estado. Com a promulgação da Lei 11.1268. de 09 de fevereiro de 1998, o governo do Estado do Rio Grande do Sul instituiu 0 Programa de Avaliação de Produtividade Docente, que divulga critérios para concorrer ao Prêmio de Produtividade Docente aberto a todos os professores da rede pública de ensino. 0 programa seria coordenado por um Comitê de Avaliação da Produtividade Docente, formado por representantes do magistério público estadual, alunos e associações de pais e mestres. 0 "Prêmio de Produtividade Docente" consistia em uma recompensa em dinheiro para aqueles cujos alunos obtivessem aprovação no processo de avaliação externa promovido pela SEE/RS. Esta prática gerencialista vinha sendo discutida em nível internacional e nacional, pois "Entre os paises em desenvolvimento, o Brasil foi o primeiro a iniciar uma Reforma Gerencial" (BRESSER-PEREIRA, 2008, p. 148). A Reforma Gerencial estava sendo tratada desde 1995 em âmbito federativo, quando, analisada sob o ângulo da gestão evidenciava que as instituições públicas vinham elaborando planos estratégicos na busca de uma administração por resultados o que era destacado como "sistemas de gestão baseados na motivação positiva dos servidores públicos que alcançam metas ou

\footnotetext{
8 Atualmente a SEC/RS estrutura um novo modelo de avaliação das escolas públicas, lançando-o em 25 de setembro de 2012 (http://www.educacao.rs.gov.br/pse/html/seap.jsp?ACAO=acao1). Neste sistema de avaliação as comunidades escolares - pais, funcionários, alunos e professores - participam. São seis dimensões: Gestão institucional, espaço físico, organização e ambiente de trabalho, políticas de acesso, permanência e sucesso na escola, formação de profissionais da educação e práticas pedagógicas e de avaliação. As dimensões são desdobradas em sub-indicadores para o ambito macro e micro do sistema de ensino.
} 
apresentam melhores desempenhos" (BRESSER-PEREIRA, 2008, p. 148). Este Programa de Avaliação da Produtividade Docente, entretanto, não foi implementado, com o que não houve de fato premiações ou gratificações vinculadas à produtividade dos docentes. No período de 1999 a 2002, no governo de Olívio Dutra, Partido dos Trabalhadores, a orientação era romper com as avaliações externas no estado. Entretanto, o governador Tarso Genro do Partido dos Trabalhadores, cuja gestão iniciou em 2011, retoma a avaliação externa das escolas da rede pública estadual ${ }^{9}$.

\section{Sistema de Avaliação do Rendimento Escolar no período de 2003/2006}

As propostas pautadas no Plano de Governo 2003/2006 de Germano Rigotto, apresentavam, dentre outros elementos, procedimentos de avaliação externa do aprendizado, e incentivo/estímulo para professores e alunos. Ou seja, a avaliação externa passava a ser articulada à premiação/gratificação da docência, numa linha de continuidade à proposta delineada, mas não implementada no último ano de governo de Antonio Britto Filho, quando da promulgação da Lei 11.126/1998 que instituía 0 Programa de Avaliação de Produtividade Docente.

O novo governo ancorou, portanto, sua gestão na adoção da lógica gerencial, adotando o estabelecimento de metas, avaliação e premiação. Essa prática veio comprovada com a promulgação da Lei 12.237, de 14 de janeiro de 2005, que normatizava a política de produtividade e qualidade decorrente da racionalização dos recursos e despesas no âmbito do Poder Público. Fortalecia-se assim a gestão por resultados na administração da educação pública no Estado uma vez que, "o governo de Germano Rigotto teve como propósito buscar mudanças administrativas que apostassem para um novo modelo de serviço público" (AMARAL, 2010, p. 92).

Esta Lei versava sobre o Contrato de Gestão, publicado no DOE no 09, de 14 de janeiro de 2005 para exercício de 2005 e 2006, considerado como o "principal mecanismo do Programa de Modernização da Gestão Pública (AMARAL, 2010, p. 128). 0 objetivo destes Contratos era estabelecer metas de desempenho a serem cumpridas, pelos órgãos públicos, com efeito cascata dentro da SEE/RS. Desta forma, na pasta da Educação, em setembro de 2005, foi firmado o Contrato de Gestão entre o Governo

${ }^{9}$ Este Projeto previa também que vários seriam os produtos e serviços contratados: as atividades de cadastro de escolas, identificação das turmas e alunos; elaboração das provas, questionários e manuais de procedimentos; impressão de todo o material; condições de empacotamento, distribuição e recolhimento dos instrumentos; correção e processamentos dos dados das provas, dos questionários de alunos, professores e diretores ou supervisores; organização da base de dados de maneira estruturada em arquivos por Município, rede de ensino, escola, série/ano, turno e turma disponibilizando estes dados à SEE/RS e às Secretarias Municipais que participassem do SAERS/2005. Estava firmado também que a análise estatística dos dados seria de acordo com a Teoria da Análise Clássica e a Teoria de Resposta ao Item - TRI; a organização da base de dados seria feita com as respostas das provas dos alunos, dos questionários dos alunos, dos professores, dos diretores ou supervisores, e sobre a infraestrutura da escola com base na leitura ótica das folhas de respostas. 
do Estado do Rio Grande do Sul e a SEE/RS, com interveniência da Secretaria da Coordenação e Planejamento (SCP), com base na Lei Estadual no 12.237/2005 com vigência, a partir de sua assinatura, até 31 de dezembro de 2006.

Objetivando o cumprimento dos Contratos de Gestão foram estabelecidos Subcontratos de Gestão com metas, indicadores e objetivos específicos, para o ano de 2005, entre a SEE/RS e as escolas públicas estaduais, através de seus diretores, com interveniência de suas respectivas Coordenadorias Regionais de Educação. Os contratos seguiam uma lógica de abrangência progressiva e comprometimento com metas a serem alcançadas pelos diferentes níveis, embora somente duas Coordenadorias Regionais de Educação fossem envolvidas, a $25^{\text {a }}$ e a $32^{\text {a }}$ CREs, com sede, respectivamente, em Soledade e São Luiz Gonzaga.

Os indicadores de qualidade e produtividade do ensino acordados no Subcontrato de gestão foram: Indicador de Abandono Escolar no Ensino Fundamental; Indicador de Reprovação no Ensino Fundamental; Número de Alunos por Professor; Índice de Satisfação da População com a Escola Pública; Indicador Global de Desempenho; Índice de Aproveitamento escolar - nota - média de Matemática e Português em cada série. Sabe-se que os indicadores são empregados na "forma de instrumentos de produção de mudanças" da cultura da escola, principalmente no que tange à busca de metas, planejamento estratégico e resultados, o que conduz a julgar e comparar o trabalho dos profissionais por meio dos resultados atingidos (WERLE; MANTAY; ANDRADE; 2009, p. 141).

Em 01 de setembro de 2005 a SEE/RS e a União Nacional de Dirigentes de Educação Secção Rio Grande do Sul (UNDIME/RS) firmaram parceria com o propósito de retomada do Sistema de Avaliação, agora sob a denominação de Sistema de Avaliação do Rendimento Escolar do Rio Grande do Sul (SAERS). Por outro lado, e em conformidade com o previsto na Lei 12.237/2005 que normatizava os Contratos e os Subcontratos de Gestão, em 28 de Setembro de 2005, foram assinados os Subcontratos de Gestão entre a SEE/RS e as escolas que participariam do processo. É preciso salientar que para o desenvolvimento do SAERS/2005 foi editado um Projeto Básico de Avaliação/2005 que serviria de orientação nos aspectos técnicos, operacionais e metodológicos do processo de avaliação de 2005 para a empresa terceirizada ${ }^{10}$ que o executaria. Não seria, portanto, um processo realizado diretamente pela hierarquia e estrutura administrativa da SEC/RS mas delegado a uma empresa especializada ${ }^{11}$, externa ao aparelho estatal.

10 0 processo de licitação teve como vencedora a Fundação Cesgranrio. A Fundação Cesgranrio, a partir de 1995 passou a elaborar e aplicar o projeto do Sistema de Avaliação do Ensino Básico usando a pela primeira vez no Brasil a TRI. Desde então, coube à ela a aplicação da quase totalidade das avaliações nacionais: o "Provão", desde 1996, substituído atualmente pelo Exame Nacional de Avaliação do Desempenho dos Estudantes ENADE; o ENEM - desde 1998; o ENCCEJA -em 2002 e 2007 e a Prova Brasil, de 2005 e 2007. Além das avaliações nacionais, a Fundação Cesgranrio tem realizado avaliações do sistema de ensino em vários Estados, como o SPAECE, no Ceará, o SARESP em São Paulo, o SIADE - do Distrito Federal, o Nova Escola, no Estado do Rio de Janeiro; e o do Rio Grande do Sul- SAERS. (FUNDAÇÃO CESGRANRIO, 2011).

11 Olívio Dutra do PT foi governador do Estado neste período, momento em que as avaliações em larga escala propostas pela instância estadual foram desativadas.

Ensaio: aval. pol. públ. Educ., Rio de Janeiro, v. 20, n. 77, p. 677-700, out./dez. 2012 
Este projeto pontuava que o SAERS tinha por objetivo diagnosticar as habilidades cognitivas na área de Leitura/Escrita e Matemática e por finalidade fornecer subsídios para a correção de políticas educacionais, visando, além da qualidade do ensino, à autonomia da escola, ao estabelecimento de parcerias com diferentes segmentos e ao desenvolvimento de uma cultura de avaliação que envolvesse toda a comunidade escolar.

Para consolidar, portanto, toda a metodologia de articulação entre os procedimentos de avaliação e os gerenciais voltados ao alcance de melhores índices de produtividade, o governador emite o Decreto $n^{\circ} 44.045$, de 04 de outubro de 2005, que dispõe sobre o Contrato de Gestão, o Subcontrato de Gestão e a premiação por produtividade. Ou seja, formaliza-se o que os outros documentos anunciavam e a nova gestão pública gerencial adquire concretude.

Estava presente a preocupação com a comparabilidade dos dados estaduais com os nacionais produzidos pelo $S A E B$, focando especialmente os da $5^{a}$. série $/ 6^{\circ}$. ano. Diferentemente das avaliações aplicadas nos anos de 1996 a 1998 os questionários de contexto atingiram o conjunto dos alunos envolvidos na avaliação. Professores e diretores ou supervisores também responderiam a um questionário que envolvia sua formação profissional, práticas pedagógicas, nível socioeconômico e cultural, estilos e formas de gestão, clima acadêmico e disciplinar da escola, recursos pedagógicos e humanos. Os aplicadores também deveriam responder a questões sobre a infraestrutura das escolas que participaram do SAERS/2005.

Diferente das provas de 1996/1998 onde os alunos responderam a apenas uma prova de uma disciplina, em 2005, os alunos respondiam a questões de Português e Matemática na mesma prova. A avaliação que ocorreu no ano de 2005 estava firmemente associada a um projeto de gestão por resultados o qual foi desenvolvido, na íntegra, em apenas duas regiões do Estado. Firmaram o Subcontrato de Gestão 117 escolas estaduais, embora tenham participado 115, devido à disponibilização de resultados. 0 total de alunos participantes foi 19.707, sendo 11.432 da $25^{a}$ CRE, com regional em Soledade e,

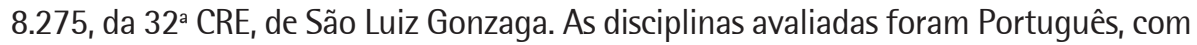
Redação, e Matemática; as séries envolvidas foram as $2^{\mathrm{a}}$ e $5^{\mathrm{a}}$ séries somente do Ensino Fundamental. Das escolas que participaram, 37 foram premiadas, sendo 23 , da $25^{\text {a }} \mathrm{CRE}$ e, 14, da $32^{\text {a }}$ CRE. 0 total repassado pelo Estado nesta avaliação foi $R \$ 376.000,00$.

A meritocracia inserida através da premiação às escolas que alcançaram os melhores desempenhos reforça a individualização e a responsabilização da escola no alcance das metas, desconsiderando as diversidades de cada instituição e outros fatores que interferem no processo de aprendizagem dos alunos (DRABACH, 2010). Amaral (2010, p. 131) em sua tese de doutorado, ao analisar as premiações das escolas que participaram da avaliação, considera que, uma escola com número reduzido de alunos e de professores, situa-se em melhores condições pois a "articulação pedagógica torna-se mais fácil e eficaz". 
Tal como nos temos posicionado ao longo deste artigo, Souza e Oliveira (2003, p. 879) esclarecem que estas iniciativas de avaliação "têm servido para viabilizar uma lógica de gerencialismo da educação" ao divulgar a ideia de produção da qualidade da educação. A avaliação se torna um mecanismo de controle, não considerando a aprendizagem como um processo e sim como um produto da "ação da escola, certificando sua qualidade". Ressaltam ainda, que a avaliação "legitima valorações" que conduzem a competitividade entre as instituições e profissionais da educação via desempenho/financiamento. Ora, esta lógica gerencialista apontada por Souza e Oliveira emerge tambem dos processos de avaliação em larga escala adotados no RS. Nas edições de 1996 e 1997 ela não estava clara, mas na de 1998 ela se faz visível como concepção, embora não implementada. Nos anos de 1999 a 2001 o processo de avaliação em larga escala promovido pela SEE/ RS foi interrompido ${ }^{12}$, sendo retomado em 2005.

Essa lógica gerencialista busca aumentar a eficiência e eficácia das escolas através de indicadores de desempenho ou de resultados, envolvendo: controles estatísticos, sistemas avaliativos, ranqueamentos. Para o governo é uma forma de regular o sistema educacional, pois, como afirma Ball (2004, p. 1116), inseria-se "profundamente nas culturas, práticas e subjetividades das instituições do setor público e de seus trabalhadores, sem parecer fazê-lo". Os sistemas de avaliação de 1996 a 1998 apresentavam elementos que apontavam no sentido da gestão democrática. Lembrando Dourado (2007, p. 924) "a gestão educacional tem natureza e características próprias, ou seja, tem escopo mais amplo do que a mera aplicação dos métodos, técnicas e princípios da administração empresarial, devido à sua especificidade e aos fins a serem alcançados". Esta gestão democrática pronunciada na Constituição Federal e na Lei 9394/96 torna-se esbatida na intencionalidade das propostas da Lei 11.126/98, com o anúncio do Programa de Avaliação da Produtividade Docente e nos procedimentos que sustentam os Contratos de Gestão dos anos de 2005 e 2006.

O SAERS/2005 aplicado em escolas de duas regiões do RS não faz referência à Lei de Gestão Democrática que institui um Sistema de Avaliação em todas as escolas de rede estadual pública. Ademais, sua abrangência restringia-se a alunos do Ensino Fundamental, excluindo os alunos do Ensino Médio que já haviam participado de avaliações nos anos de 1996/1997/1998.

12 (CAEd) Centro de Políticas Públicas e Avaliação da Educação, da Universidade Federal de Juiz de Fora, é uma instituição que elabora e desenvolve programas de avaliação sobre o rendimento escolar dos alunos de escolas públicas, promovidos pelas Secretarias Estaduais de Educação. Também cria e promove cursos de formação, qualificação e aprimoramento aos profissionais da Educação de diversos Estados do Brasil, além de desenvolver software para a gestão de escolas públicas (como por exemplo, os projetos SisLame e SIMADE) com o objetivo de modernizar a gestão educacional. 0 CAEd também presta serviços de apoio para o desenvolvimento de projetos educacionais promovidos por iniciativas privadas, a exemplo de algumas ações da Fundação Roberto Marinho, do Instituto Unibanco e da Fundação Oi Futuro. As áreas de atuação do CAEd são: formação, pesquisa, gestão e avaliação. Fonte: http://www.caed.ufjf.br/site/?id=5 consulta em 12/12/2011. 
Com a não expansão dos Contratos e Subcontratos de Gestão, as avaliações nos anos seguintes deste governo não ocorreram. 0 retorno ao processo de avaliação em larga escala se deu na gestão de 2007 a 2010, no governo de Yeda Rorato Crusius.

\section{Sistema de Avaliação do Rendimento Escolar - período de 2007/2010}

Junto ao movimento - Compromisso Todos pela Educação - que acontecia em âmbito nacional desde 2006, o Estado do Rio Grande do Sul implementou um programa chamado Agenda 2020 - 0 Rio Grande que Queremos.

A Agenda 2020 é um conjunto de projetos com vista ao desenvolvimento do Estado. Entre suas propostas, figurava a Educação, com o objetivo de "construir propostas concretas de interesse do conjunto da sociedade rio-grandense a partir da ideia de transformar o Rio Grande do Sul no melhor Estado para se viver e trabalhar" (ABREU, 2011, p. 60).

A governadora eleita para o período 2007 - 2010 apresentou seu Plano de Governo com a proposta de construir "um novo jeito de governar" (RIO GRANDE DO SUL, 2007/2010, p. 2), o que envolvia três eixos de ação: Desenvolvimento Econômico e Sustentável, Desenvolvimento Social e Finanças e Gestão Pública. Dentre as metas propostas no Desenvolvimento Social estava a Educação. Identificado com o movimento Compromisso Todos pela Educação, o governo reafirma as metas da Agenda 2020 e lança Os Programas Estruturantes. Estes foram sendo construídos a partir de 2007 sob a ótica de um novo "modelo de gestão por resultados" (ABREU, 2011 p. 61), que veio instituído pelo Decreto 45.273, de 04 de Outubro de 2007, que, normatizava a implementação da "Modernização da Gestão Pública" sob a perspectiva de um gerencialismo intensivo dos Projetos e Programas.

Os Programas Estruturantes adotavam uma hierarquia de gerenciamento intensivo onde, o Secretário seria o primeiro responsável, seguido de um Coordenador do Programa e, por fim, de um Gerente do Projeto. Cada Programa Estruturante tinha um Termo de Compromisso de Resultados (TCR), elaborado pela Secretaria do Planejamneto e Gestão, firmado entre a governadora, o Secretário responsável, o Coordernador Executivo e os Gerentes dos Projetos.

Os Programas Estruturantes eram compostos por programas articulados entre si nos eixos. No eixo Desenvolvimento Social, encontrava-se o Programa Boa Escola Para Todos. Entre os projetos vinculados a este Programa estava o Sistema de Avaliação do Rendimento Escolar do Estado do Rio Grande do Sul (SAERS), cujas ações previstas eram a avaliação do Ensino Fundamental e o Projeto Alfabetização voltado para alunos com seis anos de idade, matriculados no $1^{\circ}$ e $2^{\circ}$ anos do Ensino Fundamental de 9 anos.

Assim, frente a este contexto de gerenciamento intensivo de projetos com a constituição de equipes de responsabilização pelo acompanhamento dos programas, 
foi que a SEE/RS, passou a orientar o Sistema de Avaliação do Rendimento Escolar do Estado do Rio Grande do Sul (SAERS), para a gestão 2007/2010. Neste contexto não se identificam traços de gestão democrática com participação da comunidade escolar nas decisões. Ao contrário, a cascata de decisões desencadeada pela hierarquia do governo e implicava compromissos, exigências e metas visando à "modernização da gestão pública", afastando-se da gestão democrática da escola pública.

Em 2007, iniciaram-se estudos que culminaram com uma nova parceria firmada entre a Secretaria da Educação do Rio Grande do Sul (SEE/RS), a União Nacional de Dirigentes Municipais de Educação (UNDIME/RS) e o Sindicato dos Estabelecimentos do Ensino Privado no Estado do Rio Grande do Sul (SINEPE/RS) - cujo objetivo era a retomada do processo de avaliação externa das escolas públicas, já implantado nos anos de 1996, 1997, 1998 e 2005.

Em setembro de 2007, a SEE/RS emitiu o documento - Projeto Básico do Sistema de Avaliação do Rendimento Escolar do Rio Grande do Sul (SAERS)/2007 - Ensino Fundamental e Ensino Médio, cujas definições técnicas, operacionais e metodológicas orientariam a quinta edição do SAERS, e indicariam os produtos e serviços a serem contratados, com uma empresa terceirizada por meio de processo licitatório.

Os objetivos do Projeto/2007 eram diagnosticar as habilidades cognitivas nas áreas de Língua Portuguesa e Matemática nos alunos de $2^{\mathrm{a}}$ série $/ 3^{\circ}$ ano e $5^{\mathrm{a}}$ série $/ 6^{\circ}$ ano do Ensino Fundamental e $1^{\circ}$ ano de Ensino Médio e contribuir para ampliar a competência do professor na área de avaliação e na busca de alternativas didáticas mais adequadas ao processo de aprendizagem dos alunos. Frente às avaliações implementadas pelo governo federal, as séries abrangidas eram uma diferenciação.

Quanto à finalidade do SAERS, o mesmo documento reiterava o que já vinha explícito no Projeto/2005, ou seja, forneceria subsídios para a correção de políticas educacionais, visando à qualidade do ensino, à autonomia da escola, parcerias com outros segmentos sociais e o desenvolvimento de uma cultura de avaliação.

A empresa contratada para a elaboração do SAERS/2007 foi o Centro de Políticas Públicas e Avaliação da Educação (CAEd) ${ }^{13}$-, da Universidade Federal de Juiz de Fora.

13 (CAEd) Centro de Políticas Públicas e Avaliação da Educação, da Universidade Federal de Juiz de Fora, é uma instituição que elabora e desenvolve programas de avaliação sobre o rendimento escolar dos alunos de escolas públicas, promovidos pelas Secretarias Estaduais de Educação. Também cria e promove cursos de formação, qualificação e aprimoramento aos profissionais da Educação de diversos Estados do Brasil, além de desenvolver software para a gestão de escolas públicas (como por exemplo, os projetos SisLame e SIMADE) com o objetivo de modernizar a gestão educacional. 0 CAEd também presta serviços de apoio para o desenvolvimento de projetos educacionais promovidos por iniciativas privadas, a exemplo de algumas ações da Fundação Roberto Marinho, do Instituto Unibanco e da Fundação Oi Futuro. As áreas de atuação do CAEd são: formação, pesquisa, gestão e avaliação. Fonte: http://www.caed.ufjf.br/site/?id=5 consulta em 12/12/2011. 
Assim, a partir do Projeto Básico de Avaliação/2007, a governadora do Estado, através

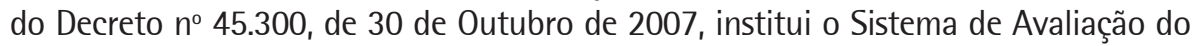
Rendimento Escolar do Rio Grande do Sul (SAERS) sob a coordenação e execução da SEC/RS, por intermédio do Departamento de Planejamento. O SAERS seria aplicado em todas as escolas estaduais urbanas e rurais, com periodicidade não superior a 2 anos, podendo escolas municipais e particulares aderirem ao processo. Como na edição de 2005 o SAERS compunha-se de testes respondidos por alunos, e questionários de contexto ${ }^{14}$.

Normatizava ainda que os resultados deveriam ser analisados com base na Teoria de Resposta ao Item (TRI), apresentados na escala de proficiência do SAEB e divulgados por turma, escola, CREs e conjunto da rede estadual.

Participaram do SAERS/2007, 3.296 escolas e 325.485 alunos, sendo 2.715 escolas da rede estadual de ensino, com um total de 288.734 alunos e 562 escolas municipais com 33.337 alunos, 18 escolas da rede particular com 3.116 alunos e uma federal com 298 alunos.

Após as avaliações e de acordo com a normativa do Projeto Básico de Avaliação/2007, o CAEd deveria enviar para a SEE/RS e estas para as escolas os Boletins Pedagógicos/2007, contendo os resultados por turma, escola e conjunto das escolas públicas estaduais avaliadas no Estado, os quais deveriam ser considerados para: a formação continuada de professores, a divulgação das práticas desenvolvidas pelas escolas com os melhores resultados e a identificação das escolas que apresentassem resultados não satisfatórios na aprendizagem de seus alunos para apoio do poder público. A devolução para as escolas ocorreu por meio de cinco Boletins Pedagógicos de Avaliação da Educação - SAERS/2007: um para a $2^{\text {a }}$ série $/ 3^{\circ}$ ano e dois (um em Língua Portuguesa e outro em Matemática), para a $5^{\mathrm{a}}$ série $/ 6^{\circ}$ ano do Ensino Fundamental e dois (um em Língua Portuguesa e outro em Matemática) para o $1^{\circ}$ ano do Ensino Médio. Estes boletins estabeleciam comparação entre os resultados, a necessidade de revisão dos processos escolares, com a idéia de uma viagem pelos caminhos da avaliação em larga escala, sendo cada capítulo denominado estação e, a travessia deveria ocorrer em encontros de discussões com os professores, a equipe diretiva e a equipe pedagógica da escola.

Para que as escolas tivessem conhecimento dos níveis de desempenho em que se encontravam seus alunos, os Boletins Pedagógicos de Avaliação apresentavam quadros

\footnotetext{
${ }^{14}$ As provas da $2^{\text {a }}$ série $/ 3^{\circ}$ ano, $5^{\mathrm{a}}$ série $/ 6^{\circ}$ ano do Ensino Fundamental e do $1^{\circ}$ ano do Ensino Médio eram objetivas com questões de múltipla escolha. Cada caderno de prova era numerado. Os de numeração par iniciavam com os blocos de Português e os cadernos ímpares com os blocos de Matemática. Além dos testes, alunos, professores, diretores ou supervisores e aplicadores também deveriam preencher um questionário, com a finalidade de avaliar o rendimento escolar e as condições internas e externas à escola que interferem no desempenho escolar. Professores e diretores ou supervisores também responderam a um questionário que envolvia sua formação profissional, práticas pedagógicas, nível socioeconômico e cultural, estilos e formas de gestão, clima acadêmico e disciplinar da escola, recursos pedagógicos e humanos. Os aplicadores também responderam a questões sobre a infra-estrutura das escolas que participaram do SAERS/2007.
} 
que demonstravam as habilidades agrupadas em cada uma das competências com seus referidos descritores da Matriz de Referência. Desta maneira, os niveis de desempenho ${ }^{15}$ representavam os resultados da avaliação e facilitavam seu uso e entendimento pela equipe diretiva, coordenação pedagógica, professores, pais e alunos. Para cada uma das disciplinas a escala era única, mas diferente, uma para Língua Portuguesa (a escala variando de 0 a 500 pontos) e outra para Matemática (de 0 a 1000 pontos). As séries avaliadas, em 2007 ficaram com rendimento médio próximo à pontuação mínima do nível Básico.

A sexta edição do SAERS/2008 seguiu o mesmo desenho metodológico do SAERS/2007. A grande diferença que veio explícita no Projeto Básico/2008 foi na estrutura e organização dos Boletins Pedagógicos de Avaliação que deveriam ser enviados às escolas, os quais deveriam organizar-se em: Elementos pré-textuais, Elementos textuais e Elementos pós-textuais. Quanto à estrutura das provas, 0 Projeto Básico/2008, apresentava o mesmo número de questões por série e disciplina.

Tal como na edição de 2007, os alunos $2^{\text {a }}$ série/ $3^{\circ}$ ano do Ensino Fundamental responderiam às questões, na capa do caderno (idade, sexo e frequência à pré-escola) e os da $5^{\mathrm{a}}$ série/ $6^{\circ}$ ano do Ensino Fundamental e do $1^{\circ}$ ano Ensino Médio questões sobre contexto socioeconômico e cultural e sua trajetória de escolarização. Professores, diretores ou supervisores e os aplicadores também responderam a um questionário.

O SAERS/2008 ocorreu nos dias de 02 a 05 de dezembro de $2008^{16}$. Participaram 0 total de 2.724 escolas e 246.886 alunos, destas 2.689 escolas e 243.584 alunos eram da rede pública estadual. Além de 19 escolas municipais com 610 alunos, havia 15 escolas particulares com 2.422 e uma escola federal com 270 alunos. As disciplinas e séries avaliadas foram as mesmas do SAERS/ 2007, mas houve um decréscimo tanto no número de escolas quanto de alunos participantes da avaliação de 2007 para a de 2008. As escolas da rede estadual tiveram uma baixa de 26 instituições e de 45.150 alunos. As escolas da rede municipal praticamente desapareceram do sistema pois, a adesão reduziu de 562 para 19 escolas e de 33.337 estudantes para 610. As escolas da rede privada também reduziram-se fortemente, passando a apenas três e 694 alunos. A escola federal permaneceu a mesma, entretanto o número de alunos participantes

15 Os níveis estavam divididos em quatro padrões: Abaixo do Básico, Básico, Adequado e Avançado. Demonstrando o desempenho dos alunos do nível mais baixo para o mais alto. Conforme a pontuação atingida pelos alunos em cada série e por disciplina o resultado indicará em que nível de desempenho os alunos se encontram.

${ }^{16}$ Antes de ocorrer o SAERS/2008, aconteceram no Estado uma série de reuniões com técnicos da SEE/RS, Coordenadores Regionais das CREs, diretores e vice-diretores de escolas. Em Maio de 2008, foram 22 notícias divulgadas no site da SEE/RS sobre os encontros que estavam acontecendo. Os temas discutidos referiam-se aos Boletins Pedagógicos da Avaliação do SAERS/2007 que estavam chegando às escolas, a análise dos dados e o uso dos resultados para auxiliar no diagnóstico das dificuldades de ensino e aprendizagem dos alunos e na qualificação das ações pedagógicas. Em novembro de 2008, foram mais 17 notícias divulgando, novamente encontros com as 30 CREs, diretores e vice-diretores das escolas para preparação do SAERS/2008.

Ensaio: aval. pol. públ. Educ., Rio de Janeiro, v. 20, n. 77, p. 677-700, out./dez. 2012 
reduziu-se a em 28 estudantes. 0 total de escolas participantes no SAERS/2009 apresentou uma baixa de 572 unidades e de 78.599 alunos. Esta progressiva redução da abrangência do SAERS nos permite retomar o argumento inicial, de que não foi possivel estabelecer, mediante políticas públicas estaduais de avaliação, uma cultura de avaliação pois a descontinuidade e mudança de rumo entre as propostas demonstram que as avaliações externas apresentam-se como políticas de governo e não de Estado.

Neste mesmo período, a SEE/RS, comunicou às escolas e à comunidade escolar que, no momento da matrícula, seria realizado um levantamento quanto ao perfil socioeconômico dos estudantes em questionário enviado para os pais responderem ${ }^{17}$. Os resultados do SAERS/2008 apresentaram uma pequena elevação nos niveis de habilidades e competências, com exceção da $5^{a}$ série $/ 6^{\circ}$ ano do Ensino Fundamental na disciplina de Português.

Com vista à próxima edição do SAERS que ocorreria em 2009, novamente a SEE/ RS deu início a uma jornada de reuniões que foram divulgadas no site da Secretaria de Educação do Estado. A jornada teve inicio com as coordenações regionais de forma a orientá-las nos trabalhos que, posteriormente, deveriam desenvolver com os diretores das escolas pertencentes à sua respectiva regional, como analisar e utilizar os resultados do SAERS/2008 como desenvolver formas de engajamento da comunidade escolar em discussões sobre a avaliação e como proceder à articulação dos resultados com as propostas pedagógicas das escolas.

A sétima edição do SAERS/2009 manteve a mesma parceria com UNDIME/ RS e com o SINEPE/RS e, novamente, a SEE/RS emitiu um Projeto Básico de Avaliação/2009 visando a orientar o processo no Estado ${ }^{18}$. A aplicação ocorreu em todas as escolas estaduais urbanas e rurais e, nas escolas municipais e particulares que aderiram ao sistema, nas mesmas turmas e disciplinas das edições anteriores. Os Boletins que deveriam ser enviados às escolas mantiveram a mesma estrutura e organização de 2008, entretanto houve alterações nos conteúdos dos capítulos.

A preocupação da SEE/RS não era mais referente à conceituação dos elementos que compunham a avaliação e sim à contextualização dos resultados com a realidade da comunidade escolar de cada instituição - o contexto socioeconômico e cultural como fator de influência nos resultados da avaliação. Uma inovação dessa edição do Boletim Pedagógico/2009 referia-se à divulgação de experiências selecionadas

\footnotetext{
${ }^{17}$ Esta pesquisa foi enviada para as escolas, como um questionário fechado, e estas enviaram para as famílias, envolvendo questões de escolaridade, ocupação, trabalho e renda familiar aproximada. Após respondidas o material foi enviado a Secretaria de Educação que justificava que tal estudo possibilitaria atender a cada escola segundo suas necessidades. Esta atividade ocorreu no final do ano de 2008 e inicio de 2009, durante o período de rematrículas e matrículas nas escolas.

${ }^{18} 0$ Projeto Básico/2009 reportava à Lei 10.576/95 da Gestão Democrática do Ensino Público que determinava a execução de um Sistema de Avaliação em todas as escolas públicas estaduais sob coordenação da SEE/RS, com o objetivo de analisar o desempenho do sistema educacional gerando informações que auxiliassem no processo de ensino e aprendizagem.
} 
pela SEE/RS, indicando o partilhamento das boas práticas das escolas cujos alunos apresentassem rendimento escolar alto frente aos resultados alcançados no processo de avaliação anterior, para servir de estímulo a mudanças ou a reconstrução de novas práticas metodológicas de ensino e aprendizagem.

A SEE/RS orientou as escolas na análise e utilização dos resultados expressos nos Boletins Pedagógicos de Avaliação /2008. Foram encontros nas diferentes regiões do Estado, onde participaram os Coordenadores Regionais, gestores e supervisores escolares, quando os dados da avaliação eram apresentados e promovidas discussões sobre formas de engajamento da comunidade nos trabalhos e articulação dos resultados com as propostas pedagógicas. Posterior aos encontros da SEE/RS com os gestores ocorreu nas escolas, a jornada pedagógica19, momento em que a equipe diretiva, coordenação pedagógica e professores deveriam trabalhar os conteúdos dos Boletins Pedagógicos da Avaliação de 2008.

Nesse contexto, entre os dias 23 e 26 de novembro de 2009, ocorreu a sétima edição do SAERS, também realizado pelo CAEd da Universidade Federal de Juiz de Fora, abrangendo todas as escolas da rede estadual de ensino, algumas escolas municipais e 18 particulares. A expectativa de participação dos alunos da rede estadual de ensino era de 323.969 o que, comparado com o número de alunos participantes em 2008 (246.886) representaria um acréscimo de 31\%. Os Boletins Pedagógicos de Avaliação/2009 enviados às escolas apresentavam-se diferentes dos produzidos em 2007 e 2008. Estavam divididos em quatro volumes que integravam a Coleção SAERS/2009: Boletim do Programa de Avaliação Vol. I; Boletim de Resultados Gerais Vol. II; Boletim de Resultados da Escola Vol.III e Boletim Contextual Vol. IV.

0 volume IV, referente ao contexto, foi um diferencial frente às edições anteriores do SAERS. Nele dois fatores foram ressaltados: o nível socioeconômico dos alunos e a defasagem entre a idade/série, o que é relevante para a gestão pedagógica e administrativa da escola.

Os resultados do SAERS/2009 foram divulgados no site da SEE/RS. Em todas as edições, exceto entre 2007 e 2008 na $5^{a}$ série / $6^{\circ}$ ano, as turmas avaliadas apresentaram um aumento nos resultados do SAERS. Entretanto, as médias indicam que o desempenho dos alunos manteve-se no nível Básico de desempenho.

O SAERS/2009, que se reportava à Lei 10.576/1995, da Gestão Democrática do Ensino Público, estimulava uma grande expectativa com relação ao desempenho dos alunos da rede pública estadual. Foram muitos trabalhos de capacitação promovidos

${ }^{19}$ As jornadas pedagógicas são encontros normatizados no Diário Oficial, antes do inicio de cada ano letivo e que devem constar no calendário da escola. Normalmente ocorrem na primeira semana antes do inicio das aulas e durante uma semana das férias discentes. A escola tem autonomia para organizar as discussões que considerar necessárias, entretanto em oficios enviados à direção da escola foram sugeridos alguns temas, como o Projeto Pedagógico da escola, Ensino Religioso, Preconceito Racial e o SAERS. 
pela SEE/RS tanto para Coordenadores Regionais como destes para os diretores de escola os quais, por sua vez, tinham a função de articulador/multiplicador dos conhecimentos aos professores, pais e alunos. 0 contexto de gestão e política educacional do final da primeira década do século XXI, entretanto, era bem diferente do verificado nos anos noventa. Na década de 1990, a grande ênfase era a gestão democrática que incluía a eleição de diretores, a criação de conselhos escolares e criação de possibilidades voltadas para a autonomia da gestão administrativa, pedagógica e financeira e outras formas participativas. Já, ao longo da década de 2000, o foco passa para os resultados, o alcance de metas, contratos de gestão, modernização administrativa.

\section{Elementos conclusivos}

As avaliações no Rio Grande do Sul tiveram sustentação a partir da Lei no 10.576, de 14 de novembro de 1995, alterada pela Lei n. 11.695, de 10 de dezembro de 2001 e atualizada pela Lei n. 12.028, de 18 de dezembro de 2003 que dispõe sobre a Gestão Democrática do Ensino Público e dá outras providências. Entretanto, o conteúdo pertinente à avaliação externa, regulamentado pelos artigos 78, 79 e 80 que implicavam a elaboração e execução de um Sistema de Avaliação no Estado do Rio Grande do Sul, mantiveram-se na integra, sem alteração. A operacionalização, entretanto, foi sendo alterada com progressivo afastamento do eixo da gestão democrática. 0 início do sistema de avaliação da rede publica estadual gaúcha corresponde aos anos de 1996 a 1998, quando foi operacionalizado mediante coordenação da Secretaria Estadual de Educação do estado. No RS, o PMDB estava no governo e em nível nacional ocorria o primeiro mandato do presidente Fernando Henrique Cardoso do PSDB, implementando políticas de cunho neoliberal e privatizantes.

Após uma pausa de seis anos, quando o Partido dos Trabalhadores esteve no governo, a avaliação externa foi retomada, agora sob a denominação de Sistema de Avaliação do Rendimento Escolar do Rio Grande do Sul (SAERS), articulado a uma acirrada gestão gerencialista com fixação de metas e indicadores para a educação. Corria o ano de 2005 e a esta avaliação foi articulado um Projeto Piloto de Avaliação para o Ensino Fundamental, abrangendo apenas duas Coordenadorias Regionais de Educação (CREs) do Estado, vinculado a um Contrato de Gestão entre o Governo e a SEE/RS e um Subcontrato de Gestão entre a SEE/RS e as escolas pertencentes às duas CREs.

Mas foi a partir de 2007 que, sob uma proposta de um novo jeito de governar gerenciamento intensivo foram formadas equipes com a responsabilidade de coordenação e acompanhamento dos diversos Programas e Projetos - Programas Estruturantes. Entre eles encontrava-se o Programa Boa Escola Para Todos, ao qual estava vinculado o SAERS.

Quanto aos objetivos e finalidade de um Sistema de Avaliação pode-se afirmar que tiveram ênfases diferentes nas primeiras edições. Enquanto, entre 1996/1998 esboçava servir para analisar o desempenho do Sistema Educacional como um todo - Escolas, Regiões, Estado e gerar informações que subsidiassem o processo de ensino 
- aprendizagem e a gestão democrática das escolas, a partir da edição de 2005 e nas subseqüentes, direcionava para o diagnóstico das habilidades cognitivas na área de Leitura/Escrita e Matemática e para corrigir políticas públicas de forma a promover a melhoria da qualidade da educação e o desenvolvimento de uma cultura de avaliação.

A operacionalização do Sistema de Avaliação na primeira edição em 1996 foi exclusivamente realizada pela SEE/RS por intermédio do DEPLAN e da DPAI. Somente este primeiro processo foi aplicado em duas fases com apoio da Fundação de Desenvolvimento dos Recursos Humanos (FDRH). Já nas edições de 1997 e 1998 o contrato foi com a Fundação de Apoio da Universidade Federal do Rio Grande do Sul (FAURGS). A partir de SAERS /2005, a SEE/RS elaborou um Projeto Básico de Avaliação que apresentava os aspectos técnicos, operacionais e metodológicos que orientariam as atividades a serem desenvolvidas por uma empresa contratada. A empresa responsável pelo SAERS/2005 foi a CESGRANRIO e para as edições do SAERS 2007 a 2010 foi o Centro de Políticas Públicas e Avaliação da Educação - CAEd, da Universidade Federal de Juiz de Fora. Portanto, as fases iniciais foram de maior protagonismo da Secretaria estadual de educação, enquanto nas demais ocorreu o recurso de terceirização mediante empresa especializada em avaliação.

Na edição de 1996, foram avaliados Português e Matemática. Em 1997, além das disciplinas de Português e Matemática, foi introduzida a Redação. Em 1998 foram incorporadas ainda as disciplinas de Ciências no Ensino Fundamental e Física, Química e Biologia no Ensino Médio.

A partir das avaliações de 2005 , os testes foram agrupados em blocos de Português e de Matemática na mesma prova.

Após o lançamento dos resultados do Sistema de Avaliação de 1996 e de 1997, respectivamente, a SEE/RS promoveu encontros de capacitação para os professores. Já na última edição do governo de Antonio Brito Filho, em 1998, não foram encontrados registros dos resultados do processo de avaliação.

Os resultados do SAERS/2005 foram entregues à SEE/RS por meio de um relatório da Fundação CESGRANRIO. No final de cada edição do SAERS 2007 a 2009, o CAEd disponibilizou, à SEE/RS, CREs e às escolas, os Boletins Pedagógicos da Avaliação com informações pertinentes a cada avaliação. Ademais, a SEE/RS promoveu uma série de reuniões para debater o panorama da realidade do rendimento dos alunos no Estado e em cada unidade escolar.

Percebe-se no Estado do Rio Grande do Sul que, a cada governo, novas concepções modificam as práticas políticas dando um novo enfoque às políticas de avaliação. 0 processo de avaliação vem progressivamente sendo reestruturado com vistas a fornecer subsídios para gestores e docentes reavaliarem suas práticas administrativas e pedagógicas, a fim de melhorar o rendimento escolar dos alunos da rede pública 
estadual. Há, entretanto, uma descontinuidade evidente nestas políticas de forma que elas se constituem como políticas de governos específicos e não como uma política de Estado, razão pela qual não se pode falar de uma cultura de avaliação em processo de consolidação no estado. Se nas primeiras iniciativas a ação voltada para metas e associada a premiações não estava formalmente presente nas propostas de contratos e compromissos firmados, progressivamente emerge a preocupação com a produtividade e, como pano de fundo, o gerencialismo e a performatividade. Esta retomada de documentos referentes às avaliações em larga escala no Rio Grande do Sul demonstra um progressivo afastamento de propostas de gestão democrática e uma preferência por procedimentos técnicos e metodologias inspiradas nas políticas praticadas pelo governo federal em termos de avaliação dos sistemas de ensino.

\section{Referências}

ABREU, Mariza. Boa escola para todos: gestão da educação e debate sobre valorização dos professores no Rio Grande do Sul. 2007 a 2010. Porto Alegre, AGE, 2011.

AMARAL, Josiane Carolina Soares Ramos do. A política de gestão da educação básica na rede Estadual de Ensino do Rio Grande do Sul (2007-2010): o fortalecimento da gestão gerencial. 2010. Tese (Doutorado)- Faculdade de Educação. Universidade Federal do Rio Grande do Sul, Porto Alegre, 2010.

BALL, Stephen J. Performatividade, privatização e o pós-estado do bem estar. Educação e Sociedade, v. 25, n. 89, p. 1105-1126, set./dez. 2004.

Profissionalismo, gerencialismo e performatividade. Cadernos de Pesquisa, v. 35, n. 126, p. 539-564, 2005. Disponivel em: <http://www.scielo.br/scielo.php?script=sci_ arttextCtpid=S0100-15742005000300002\&tng=enEtnrm=iso>. Acesso em: 27 mar. 2012.

BOBBIO, Norberto. Política. In: BOBBIO, N; MATTEUCCI, Nicola; PASQUINO, Gianfranco. Dicionário de Politica. Brasilia: UnB, 1986. p. 954 - 962.

BONAMINO, Alicia Catalano de. Tempos de avaliação educacional: o SAEB, seus agentes, referências e tendências. Rio de Janeiro: Quartet, 2002.

BRESSER-PEREIRA, Luiz Carlos. Os primeiros passos da reforma gerencial do Estado de 1995. Revista brasileira de Direito Público - RBDP, Belo Horizote, ano 6, n.23, p.145-186, out/dez, 2008.

CAMINI, Lucia. O Processo de construção da política educacional no Rio Grande do Sul de 1999 a 2002: relações, limites, contradições e avanços. 2005, $261 \mathrm{f}$. Dissertação (Mestrado)- Faculdade de Educação. Universidade Federal do Rio Grande do Sul, Porto Alegre, 2005. 
CASTRO, Claudio de Moura Castro. Avaliar não é para amadores. In: SOUZA, Alberto de Mello e (Org). Dimensões da avaliação educacional. Petrópolis, Rio de Janeiro:Vozes, 2005.

CENTRO DE POLITICAS PÚBLICAS E AVALIAÇÃO DA EDUCAÇÃO. Institucional. Sobre o Caed. Disponivel em: < http://www.caed.ufjf.br >. Acesso em: 20 abr. 2011.

DOURADO, Luiz Fernandes. Políticas e gestão da educação básica no Brasil: limites e perspectivas.Educação e Sociedade, Campinas, v. 28, n. 100, p. 021-946, 2007.

DRABACH, Neila Pedrotti. A modernização da gestão da Escola Pública Estadual do Rio Grande do Sul: a democracia na "porta giratória". 2010. Dissertação (Mestrado)Centro de Educação. Universidade Federal de Santa Maria, Santa Maria, 2010.

FEDERAÇÃO DAS ASSOCIAÇÕES DE MUNICÍPIOS DO RIO GRANDE DO SUL Institucional. Missao. Disponivel em < http://www.famurs.com.br/>. Acesso em: 20 jun. 2011.

FONTANIVE, Nilma. 0 uso pedagógico dos testes. IN: SOUZA, Alberto de Mello e. (Org). Dimensões da Avaliação educacional. Petrópolis, Rio de Janeiro: Vozes, 2005. p. 139-173.

FREITAS, Dirce Neei Teixeira de. A avaliação da educação básica no Brasil: dimensão normativa, pedagógica e educativa. Campinas: Autores Associados, 2007.

FRANCO, Clero; BONAMINO; Alicia; ALVES, Fátima. Qualidade do ensino fundamental: políticas, seus limites e possibilidades. Educação e Sociedade, Campinas, v. 28, n. 100, p. 989-1014, out. 2007. Número especial. Disponível em: http://www.cedes.unicamp.br. Acesso em: 4 jul. 2011.

FUNDAÇÃO DE APOIO DA UNIVERSIDADE FEDERAL DO RIO GRANDE DO SUL. Institucional. Histórico. Disponivel em: <http://www.faurgs.ufrgs.br/>. Acesso em: 20 jun. 2011.

FUNDAÇÃO CESGRANRIO. Cesgranrio.Institucional. Quem somos. História. Disponivel em: <http://www.cesgranrio.org.br/institucional/historia.aspx>. Acesso em: 30 abr. 2011.

FUNDAÇÃO PARA O DESENVOLVIMENTO DE RECURSOS HUMANOS. Institucional. Apresentação. Disponivel em: <http://www.fdrh.rs.gov.br/>. Acesso em: 20 jun. 2011.

LEVI, Lucio. Governo. In: BOBBIO, N.; MATTEUCCI, Nicola; PASQUINO, Gianfranco. Dicionário de Politica. Brasilia: UnB, 1986.p. 553 - 555. 
LOPES, Valéria Virginia. Cartografia da Avaliação Educacional no Brasil. Tese (Doutorado)- Universidade de São Paulo, São Paulo, 2007.

PAULA, Ana Paula Paes de. Administração pública brasileira entre o gerencialismo e a gestão social. Rev. adm. empresas [online], v. 45, n. 1, p. 36-49, 2005. <http:// dx.doi.org/10.1590/S0034-75902005000100005>. Acesso em: 30 ago. 2011.

PESTANA, Maria Inês. 0 sistema de avaliação brasileiro. Revista Brasileira de Estudos Pedagógicos. Brasília, v. 79, n. 191, p. 65-73, jan./abr. 1998.

RIO GRANDE DO SUL. Sistema Legis. Assembleia Legislativa do Estado do Rio Grande do Sul. Decreto no 42.411, de 29 de Agosto de 2003. Aprova Estatuto Padrão para os Círculos de Pais e Mestres de escolas estaduais e dá outras providências. Disponivel em: <http://www.al.rs.gov.br/legis/M010/M0100099. ASP?Hid_Tipo=TEXTO\&tHid_TodasNormas $=46611$ \&thTexto $=$ \&tHid_IDNorma $=46611$ >. Acesso em: 2 jun. 2011.

Assembléia Legislativa do Estado do Rio Grande do Sul. Decreto n 42.411, de 29 de agosto de 2003, aprova Estatuto Padrão para os Círculos de Pais e Mestres de escolas estaduais e dá outras providências. Disponivel em: <http://www. al.rs.gov.br/legis/ M010/M0100017.asp?txtNumDocs=10> . Acesso em: 2 jun. 2011.

Plano de Governo 2007/2010. Governo Yeda Rorato Crusius. Disponível em: <http://www.seplag.rs.gov.br/upload/planoGovernoYeda_2007_2010.pdf>. Acesso em: 30 abr. 2011.

SOUZA, Sandra Z. L. de; OLIVIERA, Romualdo P. de. Políticas de avaliação da educação e quase mercado no Brasil. Educação e Sociedade, Campinas, v. 24, n. 84, p. 873-895, set. 2003.

WERLE, Flávia Obino C. Sistemas e instituições: repensando a teoria na prática. In: SIMPÓSIO BRASILEIRO DE POLÍTICAS E ADMINISTRAÇÃO DA EDUCAÇÃO, 18. , 1997, Porto Alegre, Anais ... Porto Alegre: EDIPUCRS, 1997. v. 1, p. 265-290.

WERLE, Flávia; MANTAY, Carla; ANDRADE, Alenis C. de. Direção de escola básica em perspectiva municipal. Educação, Porto Alegre, v. 32, n. 2, p. 139-149, maio/ago. 2009.

Recebido em: 27/03/2012

Aceito para publicação em: 02/10/2012 